\title{
ИССЛЕДОВАНИЕ СПОСОБОВ УЛУЧШЕНИЯ ХАРАКТЕРИСТИК И ПАРАМЕТРОВ ПРИБОРА КВ114
}

В статье рассмотрены эффекты, которые влияют на параметры и характеристики и уменьшают себестоимость изготовления прибора КВ114. Для изготовления прибора применяется мезатехнология, которая позволяет получать максимально-возможные напряжения пробоя и использует только одну фотолитографию, что приводит к снижению себестоимости изготовления пластин с кристаллами. Однако эта технология приводит к большому разбросу параметров и характеристик, а также не позволяет получить максимально возможные значения добротности и коэффициента перекрытия по емкости. Кроме того, при анализе выхода годных, было определено, что основной причиной малого выхода годных приборов является высокий уровень обратных токов.

Целью работы является определение причинь появления больших обратных токов $u$ определение технологии, позволяющей снизить уровень обратных токов при малой себестоимости изготовления пластин.

Наименьшую себестоимость изготовления приборов дают процессы с наименьшим количеством фотолитографий.

Исследование эффектов, влияющих на обратные токи, показало, что основной причиной высокого уровня обратных токов является применение никеля для формирования металлического контакта. Никель дает глубокие уровни в запрещченной зоне кремния, что значительно повышает токи рекомбинации. Для уменьшения токов рекомбинаџии необходимо применять алюминий вместо никеля. Это приводит к снижению уровня обратных токов на несколько порядков.

Для улучшения параметров и характеристик прибора без увеличения себестоимости предложен новый технологический процесс с применением слоев пористого анодного окисла кремния. В этом процессе используется только одна фотолитография, что уменьшает себестоимость изготовления пластины с кристаллами. Новая технология позволяет получить максимально-возможные значения напряжения пробоя, добротности, коэффищиента перекрытия по емкости и уменьшает разброс параметров и характеристик приборов на разных пластинах. За счет применения алюминия вместо никеля выход годных по обратным токам увеличился с 15\% до 95\%.

Ключевые слова: меза-структура, меза-технология, обратный ток,пористый анодный окисел кремния.

О.М. ФРОЛОВ

Національний університет кораблебудування ім. адмірала Макарова ORCID: 0000-0003-2186-9488

С.P. СЕЛІВЕРСТОВА

Херсонська державна морська академія ORCID: 0000-0003-1015-1593

\section{ДОСЛІДЖЕННЯ СПОСОБІВ ПОЛІПШЕННЯ ХАРАКТЕРИСТИК ТА ПАРАМЕТРІВ ПРИЛАДУ КВ114}

В статті розглянуто ефекти, які впливають на параметри та характеристики приладу $i$ знижують собівартість виготовлення приладу КВ114. Для виготовлення приладу застосується мезатехнологія, яка дозволяє отримати максимально-можливу напругу пробою та використовує тільки одну фотолітографію, щзо приводить до зниження собівартості виготовлення пластин з кристалами. Однак ия технологія приводить до великого розкиду параметрів та характеристик приладу, а також не дозволяє отримати максимально-можливі значення добротності і коефіцієнта перекриття по ємності Крім изього при аналізі виходу придатних приладів було виявлено, щчо основною причиною малого виходу придатних приладів є високий рівень зворотних струмів.

Метою роботи є визначення причини появи великих зворотних струмів та визначення технологї̈, яка дозволяє знизити рівень зворотних струмів при малої собівартості виготовлення пластин. 
Найменшу собівартість виготовлення приладів дають процеси з найменшою кількістю фотолітографій.

Дослідження ефектів, які впливають на зворотні струми, показує,щзо основною причиною високого рівня зворотних струмів є використання нікелю для формування металічного контакту. Нікель дає глибокі рівні в забороненої зоні кремнію, щзо значно підвищує струми рекомбінації. Для зменшення струмів рекомбінації необхідно використовувати алюміній замість нікелю. Це приводить до зниження рівня зворотних струмів на декілька порядків.

Для поліпшення параметрів та характеристик приладу без підвищення собівартості запропонований новий технологічний процес с застосуванням шарів пористого анодного окислу кремнію. В изьому процесі використовується тільки одна фотолітографія, щзо зменшує собівартість виготовлення пластин з кристалами. Нова технологія дозволяє отримати максимально-можливі значення напруги пробою, добротності, коефіцієнта перекриття по ємності та зменшує розкид параметрів і характеристик приладів на різних пластинах. За рахунок використання алюмінію замість нікелю вихід придатних по зворотним струмам підвищився з $15 \%$ до $95 \%$.

Ключові слова: меза-структура, меза-технологія, зворотний струм, пористий анодний окисел кремнію.

A.N. FROLOV

Admiral Makarov National University of Shipbuilding ORCID: 0000-0003-2186-9488

S.R. SELIVERSTOVA

Kherson State Maritime Academy

ORCID: 0000-0003-1015-1593

\section{RESEARCH OF WAYS OF IMPROVEMENT OF CHARACTERISTICS AND PARAMETERS OF KB114 DEVICE}

The article discusses the effects that affect the parameters and characteristics and reduce the cost of manufacturing the device KV114. For the manufacture of the device, the mesa-technology is used, which allows to obtain the maximum possible breakdown voltages and uses only one photolithography, which leads to a reduction in the cost of manufacturing plates with crystals. However, this technology leads to a large scatter of parameters and characteristics, and also does not allow to obtain the maximum possible values of the quality factor and the coefficient of overlap in capacity. In addition, when analyzing the yield, it was determined that the main reason for the low yield of suitable devices is a high level of reverse currents.

The aim of the work is to determine the cause of the appearance of large reverse currents and to determine the technology that allows to reduce the level of reverse currents at a low cost of manufacturing plates.

The lowest cost of manufacturing devices give processes with the least number of photolithographs.

A study of the effects that affect reverse currents has shown that the main reason for the high level of reverse currents is the use of nickel to form a metal contact. Nickel gives deep levels in the band gap of silicon, which significantly increases the recombination currents. To reduce recombination currents, it is necessary to use aluminum instead of nickel. This leads to a decrease in the level of reverse currents by several orders of magnitude.

To improve the parameters and characteristics of the device without increasing the cost, a new technological process using layers of porous anode silicon oxide is proposed. In this process, only one photolithography is used, which reduces the cost of manufacturing a plate with crystals. The new technology allows to obtain the maximum possible values of breakdown voltage, quality factor, overlap coefficient for capacitance and reduces the spread of parameters and characteristics of devices on different plates. Due to the use of aluminum instead of nickel, the yield on reverse currents increased from $15 \%$ to $95 \%$.

Keywords: mesa-structure, mesa-technology, reverse current, porous anodic silicon oxide.

\section{Постановка проблемы}

Полупроводниковый кремниевый прибор КВ114 (варикап) имеет следующие основные параметры и характеристики [1]:

- емкость при напряжении обратного смещения $U=4 \mathrm{~B}, C=68 \pm 14$ пФ;

- добротность на частоте $f=10$ МГц при напряжении обратного смещения $U=4 \mathrm{~B}$, $Q$ - не менее 400 ед.;

- обратный ток (ток утечки) при напряжении обратного смещения $U=115 \mathrm{~B}$,

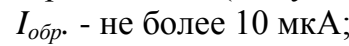

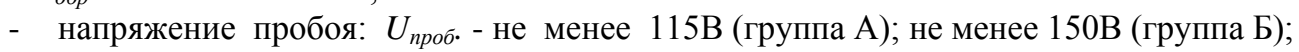

- коэффициент перекрытия по емкости $K_{c}$ - не менее 3,9 (группа А), не менее 
4,1 (группа A).

По своим параметрам и характеристикам прибор КВ114 может использоваться как варикап или как универсальный диод в слаботочных электронных цепях с напряжениями питания до $100 \mathrm{~B}$.

Прибор КВ114 изготавливается по меза-технологии на кремниевых эпитаксиальных n-n+ структурах, в которых эпитаксиальный слой n-типа имеет удельное сопротивление $\rho=4,5$ Ом 'см. Эта технология производства очень проста, включает только одну фотолитографию, что уменьшает себестоимость производства. А применение меза-структуры позволяет получать напряжения пробоя, близкие к теоретически возможным [2]. Для изготовления меза-структуры прибора применяется нанесение слоя нитрида кремния $\mathrm{Si}_{3} \mathrm{~N}_{4}$. Меза-структура создается путем травления кремния. Удаление слоя нитрида кремния проводится селективным травлением в кипящем растворе ортофосфорной кислоты. Основные этапы производства прибора КВ114 приведены на рис. 1.

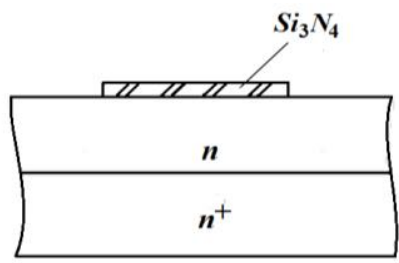

Нанесение слоя нитрида кремния $\left(\mathrm{Si}_{3} \mathrm{~N}_{4}\right)$

и 1-я фотолитография nо нитриду

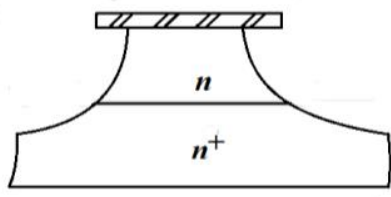

Вытравливание

меза - структуры в

смеси азотной и

плавиковой кислоты

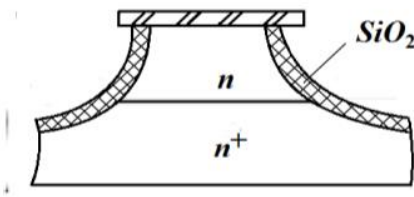

Термическое окисление

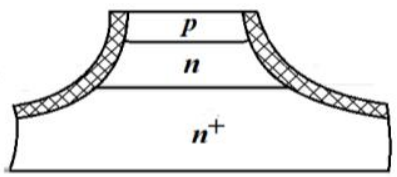

Удаление слоев

и диффузия примеси р-типа

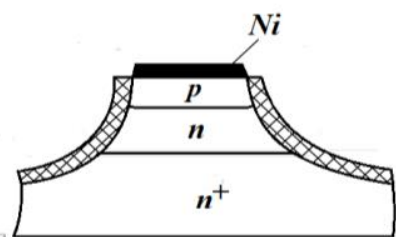

Осаждение химического никеля

Рис. 1. Основные этапы изготовления прибора КВ114

Однако на производстве прибор КВ114 имеет малый выход годных, - не более $15 \%$, что обусловливает его высокую себестоимость.

В первую очередь такой малый выход годных приборов обусловлен высоким уровнем обратных токов, которые имеют большой разброс значений и большая часть приборов имеет обратные токи больше нормы, хотя для кремниевых приборов эта норма довольно высока.

Высокий уровень обратных токов не удовлетворяет современным требованиям к приборам такого типа, и не позволяет провести отбраковку приборов с некоторыми дефектами, что уменьшает уровень безотказности.

Анализ влияния меза-структуры на коэффициент перекрытия по емкости, показал, что такая структура не позволяет получать максимально-возможных значений. 
Кроме того, на производстве выяснено, что применение меза-структуры не позволяет уменьшить разброс по площади p-n переходов для приборов с разных партий из-за особенностей процесса травления меза-структуры. А разброс по площадям приводит к разбросу параметров и характеристик диодов, что требует дополнительной настройки радиоэлектронной аппаратуры у потребителя, повышая трудоемкость и себестоимость этой аппаратуры.

\section{Анализ последних исследований и публикаций}

Недостатки прибора КВ114 обусловлены в первую очередь с применяемой технологией изготовления. В том числе:

Большой разброс по емкости. Емкость полупроводниковых p-n переходов определяется по выражению:

$$
C=S_{p-n} \cdot \sqrt{\frac{\varepsilon \cdot \varepsilon_{0} \cdot e \cdot N_{p-n}}{2 \cdot\left(U+\varphi_{k}\right)}}
$$

где: - $S_{p-n}$ - площадь p-n перехода;

- $N_{p-n}$ - концентрация примеси на p-n переходе;

- $\varphi_{k}$ - контактная разность потенциалов;

- $\varepsilon_{\mathrm{o}}$ - диэлектрическая постоянная;

- $\varepsilon$ - удельная диэлектрическая проницаемость кремния.

Из выражения (1) видно, что емкость в первую очередь зависит от площади p-n перехода. Из-за большого количества разнообразных факторов, влияющих на скорость травления меза-структуры (колебания температуры и давления окружающей среды, концентрации примеси в эпитаксиальном слое, небольшие отклонения концентрации кислот в травителе, насыщенность раствора продуктами травления, неточность в работе оператора по времени окончания процесса травления и т.д.), скорость травления кремния и глубина травления имеют значительный разброс на разных партиях пластин. Поэтому площадь p-n перехода на разных пластинах разных партий получается с большим отклонением, как показано на рис. 2. Большой разброс по площади p-n перехода приводит к появлению разброса не только по емкости, но и по добротности.

Значит, к большому разбросу по емкости приводит использование типовой меза-технологии для производства приборов КВ114.

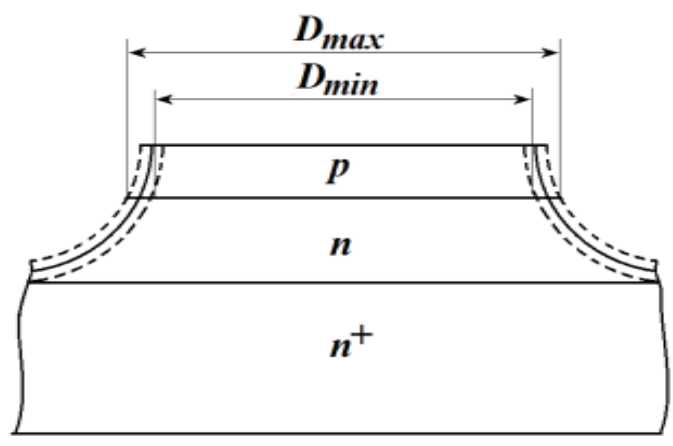

Рис. 2. Величина площади р-n переходов, получаемых при формировании меза-структуры при помощи кислотных травителей

Замена меза-технологии на технологию с планарным p-n переходом, в которой площадь p-n перехода определяется только возможностями фотолитографии, приводит к уменьшению разброса по емкости до нескольких \%, но одновременно приводит к значительному уменьшению напряжения пробоя. Применение известных способов увеличения напряжения пробоя планарных p-n переходов использованием методов охранного кольца или расширенной металлизации [2] приводит к уменьшению таких параметров, как коэффициент перекрытия по емкости $K_{c}$ или добротность $Q$. Кроме того, планарная технология требует увеличения количества фотолитографий, что увеличивает себестоимость изготовления пластин с кристаллами.

Очевидно, что альтернативой применяемой меза-технологии является технология с применением слоев пористого анодного окисла кремния [3]. Она позволяет создавать p-n переходы с максимально достижимыми напряжениями пробоя, а площадь p-n переходов определяется только возможностями фотолитографии и не зависит от размеров слоя пористого анодного окисла кремния.

Процент выхода годных и уровень обратных токов. Наибольший вклад в уменьшение выхода годных кристаллов вносит превышение уровня обратных токов над нормативным показателем (не более 
10 мкА). Гистограмма распределения обратных токов, построенная на статистике измерения 24 пластин с кристаллами из 8 партий, приведена на рис. 3.

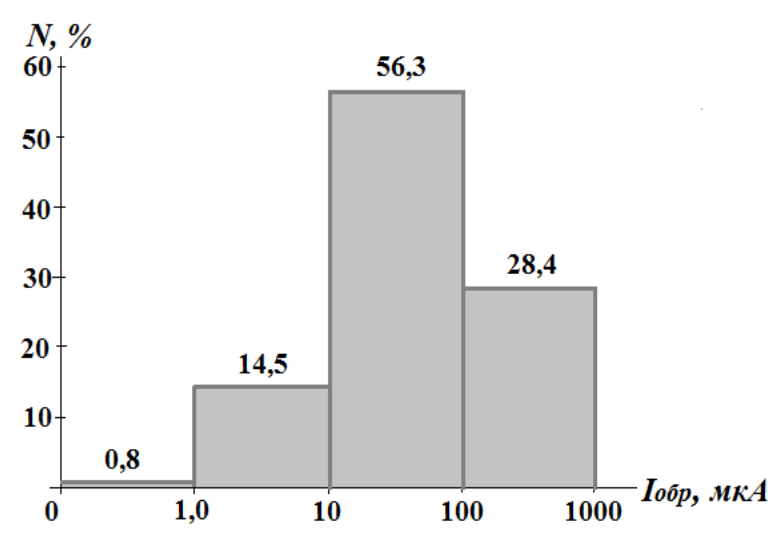

Рис. 3. Гистограмма распределения обратных токов при типовой технологии изготовления приборов КВ 114

Как видно из гистограммы, для увеличения выхода годных приборов необходимо значительно уменьшать обратные токи. Теоретически обратный ток полупроводниковых p-n переходов состоит из нескольких составляющих:

$$
I_{\text {обр. }}=\boldsymbol{I}_{\Gamma . \text { Опा }}+\boldsymbol{I}_{\Gamma . V}+\boldsymbol{I}_{S}+\boldsymbol{I}_{\text {ym.noв. }}
$$

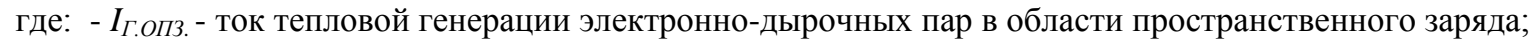

- $I_{T . V}$ - ток тепловой генерации электронно-дырочных пар в объеме полупроводниковых областей;

- $I_{S}$ - ток поверхностной рекомбинации;

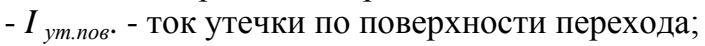

Известно, что для кремниевых приборов ток $I_{\Gamma \cdot V}$ значительно меньше, чем ток $I_{\Gamma \cdot \text { опз }}$. Также при защите p-n переходов термическим окислом очень мала величина тока утечки $I_{\text {ym.noв. }}$. Для кремниевых

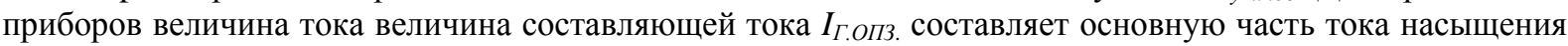
$I_{\mathrm{o}}$, который можно определить по вольтамперной характеристике (BAX) прибора при прямом смещении, используя выражение:

$$
I_{n p .}=I_{o} \cdot \exp \left(\frac{e U_{n p}}{k T}\right)-1
$$

где: - $U_{n p}-$ напряжение прямого смещения;

- $I_{n p}$ - ток при напряжении $U_{n p}$;

- $k$ - постоянная Больцмана;

- e- заряд электрона;

- $T$ - температура при измерении (в градусах Кельвина).

Расчет тока $I_{0}$ по измеренным ВАХ приборов, показывает, что этот ток составляет доли нА. Значит, в обратном токе прибора КВ114 основной составляющей может быть ток поверхностной рекомбинации.

\section{Формулирование цели исследования}

Целью работы являлось исследование вариантов технологии производства приборов КВ114 для определения способов уменьшения уровня обратных токов и повышения выхода годных приборов.

\section{Изложение основного материала исследования}

Для определения влияния конструкции и технологии изготовления прибора КВ114 на обратные токи были рассмотрены следующие предположения:

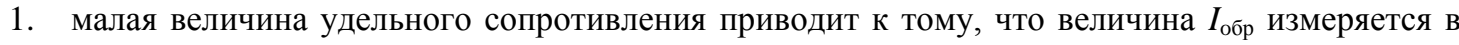
предпробойной области ВАХ при обратном смещении;

2. на обратный ток сильное влияние оказывают скрытые дефекты, которые образуются в процессе выполнения технологических операций;

3. основной составляющей обратного тока является ток поверхностной рекомбинации. 
Для проверки первого предположения, была проведена партия из 4 пластин на эпитаксиальных структурах, в которых эпитаксиальный слой имел повышенное удельное сопротивление $\rho=6,5$ Ом·см вместо $\rho=4,5$ Ом·см. Технологический процесс изготовления приборов не отличался от типового. После металлизации никелем и вжигания контакта проводилось измерение обратных токов и напряжении пробоя. Хотя напряжения пробоя в среднем увеличились на 15-20B, но распределение обратных токов почти не отличалось от представленного на рисунке 3 .

Для проверки второго предположения, что уровень обратных токов зависит от внесенных в процессе изготовления дефектов, была проведена партия из 4 пластин по типовой технологии, но с дополнительной диффузией бора в p-n переход. Предполагалось, что проведение дополнительной диффузии бора в уже созданный слой р-типа приведет к геттерированию дефектов, а это должно уменьшить уровень обратных токов. Однако при дополнительной диффузии глубина p-n перехода увеличивается. Это приводит к уменьшению напряжения пробоя по условию смыкания ОПЗ p-n перехода с низкоомной $\mathrm{n}^{+}$-подложкой, но одновременно привело к некоторому уменьшению уровня обратных токов. Гистограмма распределения обратных токов в эксперименте с дополнительной диффузией бора приведена на рис. 4.

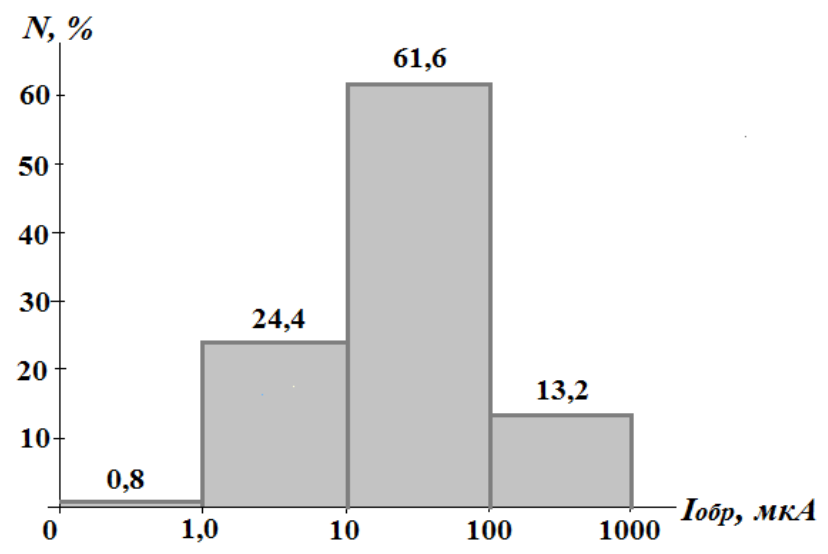

\section{Рис. 4. Гистограмма распределения обратных токов при дополнительной диффузии бора в р-области}

Как видно из гистограммы уровни обратных токов в среднем уменьшились. Однако этот эффект не может быть объяснен геттерированием, так как согласно [4] геттерирование проводится для удаления быстро диффундирующих примесей из активных областей приборов созданием геттера в неактивных областях, а область р-типа p-n перехода является активной областью. Эффект уменьшения обратных токов объясняется тем, что при дополнительной диффузии увеличивается глубина p-n перехода, a согласно [5] скорость поверхностной рекомбинации носителей заряда в полупроводниках обратно пропорциональна квадрату глубины p-n перехода, т.е. с увеличением глубины залегания p-n перехода, обратные токи уменьшаются. Это дает возможность сделать вывод, что уровни обратных токов зависят от рекомбинации носителей заряда на границе раздела никеля и кремния.

Как известно, никель дает глубокие уровни в запрещенной зоне кремния: в половине запрещенной зоны, близкой к зоне проводимости - акцепторные уровни с энергией 0,35 эВ, а в другой половине акцепторные уровни с энергией 0,23 эВ [6, 7]. Это приводит к значительной величине обратных токов из-за процессов рекомбинации носителей заряда через глубокие уровни.

Известно, что алюминий в качестве контактного металла не дает глубоких уровней в кремнии, что обуславливает его широкое применение для металлизации полупроводниковых приборов и микросхем. Однако, из-за того, что на меза-структуре с нанесенным в вакууме слоем алюминия плохо держится фоторезист, то очень сложно провести качественную фотолитографию на всех кристаллах пластины.. Кроме того, фотолитография по алюминию - это дополнительная фотолитография, что увеличивает себестоимость производства.

Технология с пористым анодным окислом кремния [3] позволяет использовать достоинства мезатехнологии не только по увеличению напряжения лавинного пробоя и по уменьшению числа технологических операций, но также позволяет создавать алюминиевый контакт вместо никелевого контакта. А это должно значительно уменьшить уровень обратных токов.

Для проверки данного варианта технологии была проведена партия из 4 пластин. Основные технологические операции проводились в типовых режимах создания прибора КВ114, с нижеприведенными отличиями. 
Вместо формирования меза-структуры путем травления кремния в кислотных травителях, после фотолитографии по нитриду, проводилось анодное окисление в режимах формирования пористого анодного окисла кремния в кипящем водном растворе борной кислоты. Режим подбирался так, чтобы высота слоя пористого анодного окисла над планарной поверхностью была в пределах 12-15 мкм.

Полученные слои пористого анодного окисла кремния имели вертикальные стенки.

После этого проводилась операция термического окисления через пористый окисел при температуре $1100^{\circ} \mathrm{C}$ в течении 45 минут в атмосфере влажного кислорода.

Удаление слоя нитрида кремния проводилось при помощи типовой операции травления в водном растворе кипящей ортофосфорной кислоты.

Металлический контакт создавался не химическим осаждением никеля, а путем вакуумного напыления алюминия термическим распылением. Из-за обрыва слоя алюминия на вертикальных стенках слоев пористого анодного окисла кремния, фотолитография по алюминию не применялась. При достаточной высоте слоев пористого анодного окисла кремния (больше чем в 10-11 раз, чем толщина слоя алюминия - 1-1,2 мкм) напыленный слой алюминия разрывается на вертикальных стенках пористого окисла [8]. В результате эксперимента получается структура прибора, показанная на рис. 5, т.е. получается отдельно алюминиевый контакт к p-n переходу и отдельно слой алюминия на поверхности пористого окисла кремния.

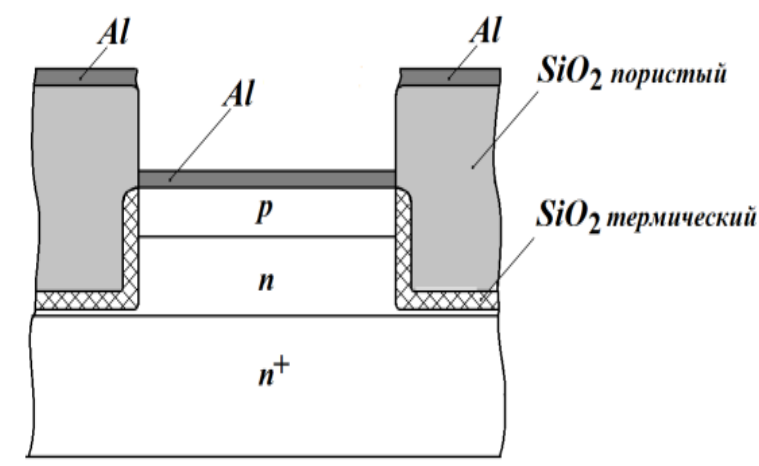

Рис. 5. Поперечный разрез структуры высоковольтного прибора, изготовленного по технологии с применением слоев пористого анодного окисла кремния

После вжигания алюминия при температуре $450^{\circ} \mathrm{C}$ в течении 25 минут в инертной атмосфере (в азоте) проводилось измерение обратных токов. Гистограмма распределения обратных токов на пластинах приборов с пористым анодным окислом кремния и алюминиевой металлизацией приведена на рис. 6.

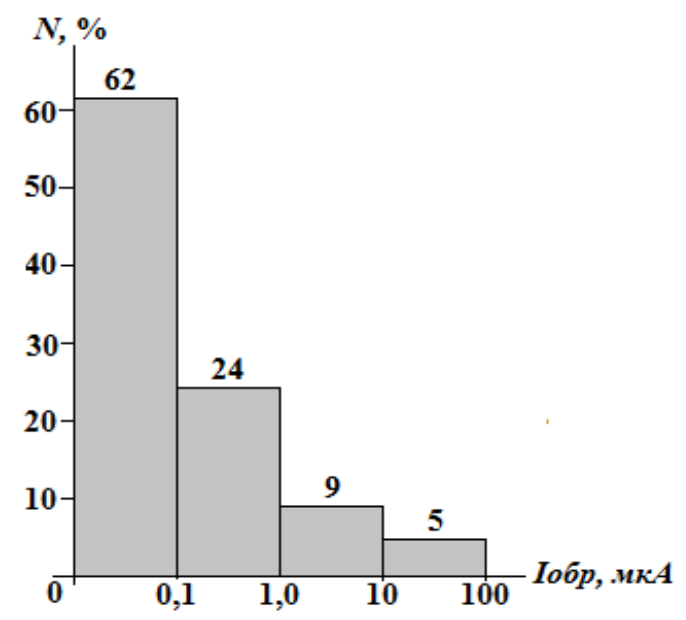

Рис. 6. Гистограмма распределения обратных токов на пластинах с пористым анодным окислом кремния и алюминиевой металлизацией

Как видно из гистограммы, уровень обратных токов по сравнению с типовой меза-технологией изготовления приборов КВ114 значительно уменьшился. Процент выхода годных кристаллов на пластине по обратным токам увеличился до $95 \%$. 
Кроме того, следует отметить, что при случайной закоротке, емкость прибора сильно не изменяется, так как емкость дополнительной структуры металл - пористый окисел - полупроводник мала из-за большой толщины пористого окисла.

\section{Выводы}

1. Основной причиной малого выхода годных приборов КВ114 являются значительные значения обратных токов, которые обусловлены применением никеля для металлизации контактов.

2. Замена никеля на алюминий в типовой технологии изготовления меза-структур прибора приводит к значительному увеличению себестоимости.

3. Меза-структура позволяет получать максимально-возможные напряжения пробоя, но приводит к большому разбросу параметров и характеристик приборов с разных партий из-за влияния различных факторов (температура, давление, время и т.д.) на процесс травления.

4. Применение новой технологии изготовления прибора КВ114 с использованием слоев пористого анодного окисла кремния позволяет:

- получать высокие напряжения лавинного пробоя, используя такие же достоинства, как и у меза-структуры;

- уменьшает разброс параметров, так как разброс глубины залегания слоев пористого анодного окисла кремния не влияет на площадь р-n перехода;

- использовать в процессе изготовления только одну операцию фотолитографии, что уменьшает себестоимость изготовления кристаллов приборов;

- приводит к уменьшению уровня обратных токов на несколько порядков, что повышает выход годных с $15 \%$ до $95 \%$.

\section{Список использованной литературы}

1. Диоды: справочник /О.П.Григорьев, В.Я. Замятин, Б.В. Кондратьев, С.Л. Пожидаев. - М.: Радио и связь, 1990. - 316с.

2. Кремниевые планарные транзисторы. Под ред. Я.А. Федотова. - М.: Сов.радио, 1973. - 336 с.

3. Фролов О.М., Шевченко В.В., Філіпщук О.М. и др. Патент на корисну модель №102197. Спосіб виготовлення високовольтних діодів зі змінною ємністю. MПК: HOIL 29/93 (2006.01), HOIL 21/31(2006.01), HOIL 21/329. (2006.01), Опубл.26.10.2015. Бюл.№20.

4. Lavine J.P. Defect site competition for metal atoms in intrinsically gettered silicon: numerical model// J. Appl. Phys. - 1987, Vol. 62, №5. - P. 1682-1688.

5. Трутко А.Ф. Методы расчета транзисторов. Издание 2-е, переработанное и дополненное.- М.: Энергия, 1971.- 272 с.

6. Зи С. Физика полупроводниковых приборов: В 2-х книгах. Книга 1. Перевод с англ.- 2-е переработанное и дополненное изд.- М.: Мир, 1984.- 456 с.

7. Матсон Э.А., Крыжановский Д.В. Справочное пособие по конструированию микросхем. Минск: Выш. школа, 1982. - 224 с.

8. Фролов О.М., Філіпщук О.М., Шевченко В.В. и др. Патент на корисну модель №120347. Спосіб виготовлення діодів зі змінною ємністю. МПК(2017.01) HOIL 21/00, HOIL 21/761(2006.01). Опубл.25.10.2017. Бюл. №20.

\section{Referenses}

1. Diods: spravochnik/O.P. Grigoryev, V.YA. Zamyatin, B.V. Kondratiev, S.L.Pozhidaev. - M.: Radio i svyaz, 1990. - $331 \mathrm{p}$.

2. Kremnievie planarnie tranzistori. Pod red. YA.A. Fedotova. - M.: Sov.radio, 1973. - 336 p.

3. Frolov O.M., Schevchenko V.V., Filipchuk O.M. i dr. Patent na korisnu model №102197. Sposib vigotovlennya visokovoltnih diodiv zi zminnoyu emnistyu. MПК: HOIL 29/93 (2006.01), HOIL 21/31(2006.01), HOIL 21/329. (2006.01), Publ.26.10.2015. Bull.№20.

4. Lavine J.P. Defect site competition for metal atoms in intrinsically gettered silicon: numerical model// J. Appl. Phys. - 1987, Vol. 62, №5. - P. 1682-1688.

5. Trutko A.F. Metodi raschota tranzistoriv. Izdanie 2-e, pererabotannoe i dopolnenoe. - M.: Energiya, 1971. -272 p.

6. Zi S. Phizika poluprovodnikovih priborov: V 2 knigah. Kniga 1/ Perevod s angl. - 2-e pererabotanoe i dopolnenoe izd. - M.: Mir, 1984. - 456 p.

7. Matson E.A., Krizhanovskiy D.V. Spravochnoe posobie po konstruirovaniyu mikroshem. - Minsk: Vish. schola, 1982. - 224 p.

8. Frolov O.M., Filipchuk O.M., Schevchenko V.V. i dr. Patent na korisnu model №120347. Sposib vigotovlennya diodiv zi zminnoyu emnistyu. МПК (2017.01) HOIL 21/00, HOIL 21/761(2006.01), Publ.26.10.2017. Bull. №20. 